OPEN ACCESS

Edited by:

Bernard Saw,

Tunku Abdul Rahman University,

Malaysia

Reviewed by:

Kok Hoe Wong,

University of Southampton,

United Kingdom

Hiew Mun Poon,

Universiti Tunku Abdul Rahman,

Malaysia

*Correspondence:

Parnuwat Usapein

parnuwat.usa@rmutr.ac.th

Specialty section:

This article was submitted to

Sustainable Energy

Systems and Policies,

a section of the journal

Frontiers in Energy Research

Received: 04 August 2020 Accepted: 28 January 2021

Published: 10 March 2021

Citation:

Meenual $T$ and Usapein $P$ (2021)

Microgrid Policies: A Review of

Technologies and

Key Drivers of Thailand.

Front. Energy Res. 9:591537.

doi: 10.3389/fenrg.2021.591537

\section{Microgrid Policies: A Review of Technologies and Key Drivers of Thailand}

\author{
Thongchai Meenual ${ }^{1,2}$ and Parnuwat Usapein ${ }^{1 *}$ \\ ${ }^{1}$ Rattanakosin College for Sustainable Energy and Environment, Rajamangala University of Technology Rattanakosin, Nakhon \\ Pathom, Thailand, ${ }^{2}$ Provincial Electricity Authority, Bangkok, Thailand
}

Microgrids have been emerging and playing valuable roles in several parts of society, from academia of scholars to the energy supply industry of professional practitioners. A microgrid policy appeared in the Thailand 2015 energy development plan. There are many microgrids in Thailand. The first smart microgrid in Thailand is in active operation. Some microgrids are no longer functioning. Other microgrids continue to serve their customers. The remaining microgrid projects are in the process of development. Most present microgrids in Thailand are driven by public policy and legal flexibility. The objective of this research is to investigate the compatible microgrid technology in Thailand and explore the key drivers of microgrid policies in Thailand. The research methodology applied in this research includes data collection (i.e., a document study, interview, group discussion, and microgrid project participation and observation), as well as data analysis and conclusion. The findings of the research show that: in Thailand, the desired microgrid technologies are compatible with 1) inputs of potential local renewable energy resources of solar, wind, biomass, and mini-hydro, and 2) small gaps of human resource capabilities to deal with the technology utilization. The key drivers of the Thailand microgrid policy are 1) electricity access, 2) wealth creation and distribution, 3) environmental protection, and 4) technology development.

Keywords: microgrid, microgrid policy, microgrid technology, renewable energy, Thailand

\section{INTRODUCTION}

Microgrids play valuable roles in several areas, from academia to the energy supply industry. Because of its beneficial renewable energy promotion, the microgrid is in various locations of lab-scale demonstration sites as well as rural and urban communities at the local, national, and future international levels (Mariam et al., 2016; Hirsch et al., 2018).

With the evolution of technology and the demand for microgrids, the microgrid has more advanced capabilities. The technological advancement of microgrid constituents often provides the improvement and the tendency of low cost (LO3 Team, 2018; Intel, 2020). The improvement is in terms of, for example, more precision, accuracy, reliability, safety, and flexibility, as well as less time consuming, human force requirement, and maintenance. In addition, they sometimes result in a low cost of investment and operation and maintenance. The demand for microgrids reflects the need for electricity access, improvement of power quality, reliability, and energy efficiency, as well as renewable energy promotion. The demand can be motivated by other economic, social, and 
technological purposes. Because of the growing demand, the microgrid market is likely to grow in the long term (IEC, 2014).

Microgrid development is a customer-driven movement, while policymakers, professionals in utilities, and regulators encounter questions related to microgrid support (Pullins, 2019). This research took this notation into account. The aim of this research is to explore the Thailand microgrid development from the perspectives of policymakers, professionals in electric utilities, and regulators.

In addition to the customer-driven movement stated in Pullins (2019), other motivations in the Thailand context of microgrid development are explored. In short, there are two main objectives of this research. Firstly, it aims at investigating Thailand compatible microgrid technology. Secondly, it has the purpose of exploring the key drivers of microgrid policies in Thailand. The expected findings of this research will provide insights for policymakers, professionals in electric utilities, and regulators.

Microgrid concepts have evolved, and microgrid projects have been developed (Romankiewicz et al., 2014; Reilly, 2019). The focus of the study was the contemporary phenomenon of microgrid development in Thailand. There was little or no control over the studied phenomenon of present-day microgrid cases. Based on these facts, this research was conducted on desks and in fields by applying the guidelines of the case study research (Yin, 2018). First hand and secondary data were collected. The data collection included a document study, interview, group discussion, and microgrid project participation and observation. A case study was conducted using collected data from Thailand microgrid cases. The collected data were analyzed, and conclusions were made.

\section{LITERATURE REVIEW}

According to the IEC62898-1 standard, a microgrid can be 1) standalone, or a subsystem of the smart grid, 2) an alternating current electrical system with loads and distributed energy resources (DERs) at low or medium voltage level, and 3) classified into an isolated microgrid and a non-isolated microgrid (IEC, 2017). The isolated microgrid has no electrical connection to the electric power system. The non-isolated microgrid can be a controllable unit in the electric power system and operated in the two modes: 1) a grid-connected mode, and 2) an island mode. Microgrid policies relate to microgrid technology and development. Several authors scrutinized microgrid technology and development.

Policymakers, entrepreneurs, and academics in the US reflected on several practical guidelines for urban microgrid developers, i.e., 1) solar energy optimization, 2) requirements for heat in terms of heating, air conditioning, and hot water, 3) cost-benefit optimization of microgrid projects to shorten a payback period, 4) multiple benefits beyond the energy backup feature, 5) multi-stakeholder investors, and 6) possibly the only solution to provide reliable electricity service in remote rural areas (C2ES Solutions Forum, 2017). Additionally, microgrid development barriers were 1) financing challenges, and 2) the need for a clear legal framework to define and set forth the rights and obligations of the microgrid owner concerning its customers and the main grid operator. Excluding heat energy, this research had considered these guidelines.

In an editorial review of the special issue of Distributed Energy and Microgrids (Wang et al., 2018), an editorial team provided insights into technological and economic topics, e.g., 1) integration of distributed energy resources such as photovoltaics, geothermal and solar heat, wind turbines, microturbines, various energy storage systems, as well as passive sources of energy services and active load control, and 2) the introduction of new components, new network configurations, new design and operation methods, and new incentives and business models, giving rise to new issues of the power system and electricity market efficiency, security, structure, and policy. The accepted papers in this special issue could be grouped into six categories: 1) DER devices (e.g., energy storage, inverters, virtual controllers); 2) economic analysis and markets; 3 ) operation and control of microgrids; 4) planning and optimization of microgrids; 5) reliability and resiliency; and 6) demand-side response (DR).

A review of microgrid development in the US showed 1) federal, state, and utility-level policies driving microgrid development in the US, 2) the selected demonstration microgrid projects to showcase technological and economic feasibility and their technical and non-technical characteristics, and 3) technology development, microgrid control methods, and microgrid interaction within the electricity market (Feng et al., 2018). The authors gave three recommendations, i.e., 1) need for clear targets of microgrid policies and demonstration projects, 2) well-defined social and economic benefits in setting up the microgrid research and demonstration projects, and 3) requirements for both feasible technologies and market mechanisms in the microgrid demonstration projects. They also suggested that the interaction of multiple microgrids, trade-offs between economic benefits and resilient performance, and direct current microgrids were the possible research areas.

In a review of microgrid development and technology, Liu (2019) expressed 1) the brief of microgrid development in the US and the EU, 2) characteristics of the microgrid, 3) type of microgrid (i.e., AC microgrid, DC microgrid, and AC/DC hybrid microgrid), 4) key technologies of the microgrid (i.e., operation control technology, protection technology, gridconnected technology, and energy storage technology), and 5) microgrid development trend. The author also pointed out that microgrids 1) had many advantages and challenges for large scale deployment, 2) were one of a central theme of research, and 3) would increase to serve technological and economic development.

The review of literature related to microgrid policy was divided into two parts: 1) technologies of microgrid constituents, and 2) microgrid policies.

\section{Review of Microgrid Technology}

The fundamental components which ensure that a microgrid can supply electricity consist of 1) distributed generation units, 2) electricity distribution systems, 3) protection and control units, 

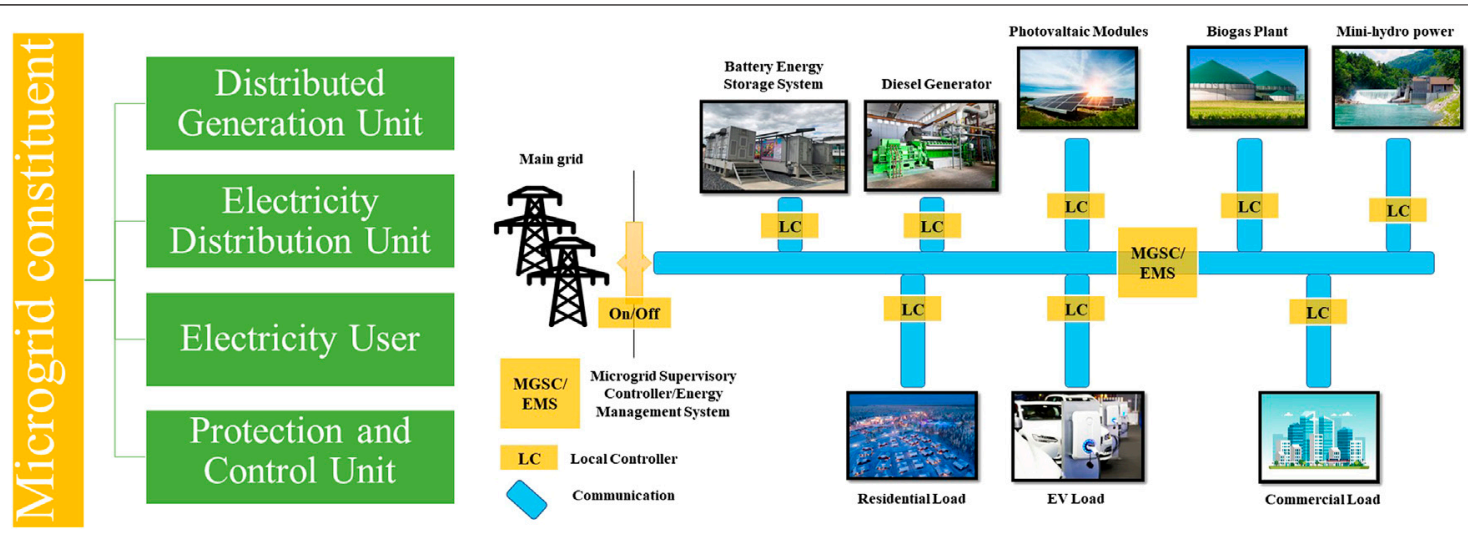

FIGURE 1 | Main microgrid constituents.

and 4) electricity users and electrical loads (Hossain et al., 2014; Mariam et al., 2016; Bullich-Massagué et al., 2018; Hirsch et al., 2018; Pachanapan, 2018). Figure 1 shows four main microgrid constituents. The objectives of the microgrid operation are, for example, 1) to balance supply and demand of electricity, 2) to reduce technical electrical system losses, 3) to prolong the life cycle of electrical equipment, 4) to raise power quality, reliability, resiliency, efficiency, and safety of electricity supply, 5) to reduce $\mathrm{CO}_{2}$ emission, 6) to decrease gaps of energy poverty and justices, as well as 7) to enlarge the access to affordable and clean electricity (Feijoo and Das, 2015; Graber et al., 2018). The optimization and advanced potential of digital and energy technologies deal with other modern components, e.g., energy storage, information and communication systems, inverter-based devices, electric vehicles (EVs), and EV charging stations. The EVs and the EV charging stations gradually emerge in residential and commercial sectors of the electricity supply industry.

\section{Distributed Generation Unit}

Distributed generation (DG) units can consist of renewable energy and non-renewable energy, fossil-based energy (Romankiewicz et al., 2014). Fossil-based DG units consume, for example, oil and gas. Conventional combustion engines play significant roles in fossil-based DG units. Renewable DG units take benefits from spatial DERs (IRENA, 2019; Reilly, 2019). Popular renewable DERs are solar, wind, biomass, biogas, mini-hydro, and geothermal. Apart from electricity generation technologies, energy storage and energy conversion technologies are functionally close to DG units (Feijoo and Das, 2015). The energy storage deployed in modern microgrids is usually lithium-ion batteries diversified from their applications in mobile devices. The energy conversion units based on power electronics convert direct current electricity to alternating current electricity, and vice versa (Kumar et al., 2019). In addition, other important DG-related technologies are embedded systems, sensors, as well as information and communication technologies.

\section{Electricity Distribution System}

Most of the electricity distribution systems are AC systems at low and medium voltage levels. In a microgrid, they functionally transmit electricity from DGs to electrical loads. Conventional technologies of poles and wires are still active. ICT-based technologies, e.g., fault detectors, monitor and management units of distribution transformers, and transformer load management systems, are added to the electricity distribution systems (Warwick et al., 2016). ICT-added technologies make electricity distribution systems more visible, controllable, manageable, and smarter (Bani-Ahmed et al., 2014; Shukla et al., 2014). In addition to wires carrying electricity, optical or copper communication wires are installed in order to transmit and exchange data. In the case of only power line carrier technologies or modulator/demodulator, multiplexer/ demultiplexer, as well as radio frequency-based and wireless communication technologies, the need for communication wires in the electricity distribution system is little, if any (Yarali and Rahman, 2012).

\section{Protection and Control Unit}

Protection and control technologies have been developed through several development stages (Bo et al., 2016). Protection technologies provide functional safety to humans interacting with grids and the electrical equipment of grids. Control technologies are used to operate microgrids smoothly. Protection units are, e.g., fuses, reclosers, switches, relays, and breakers. The control units or microgrid controllers have their unique roles of commanding, directing, and coordinating all microgrid constituents (Reilly, 2019). With a controller, a microgrid can be a controllable entity and a smart entity. Like other modern microgrid constituents, protection and control technologies, including the microgrid controller, have evolved from an analog mechanical base to a digital electronic one. The protection and control units ensure the maximum reliability of the electricity grid (Dewadasa et al., 2009).

\section{Electricity User or Electrical Load}

Electricity users need electrical energy to supply electrical machines, appliances, and devices for their daily private and working life for their comfort (Iqbal et al., 2018). Technologies related to electricity users, commonly called electrical loads, are electrical machines, appliances, and devices. They are, for 


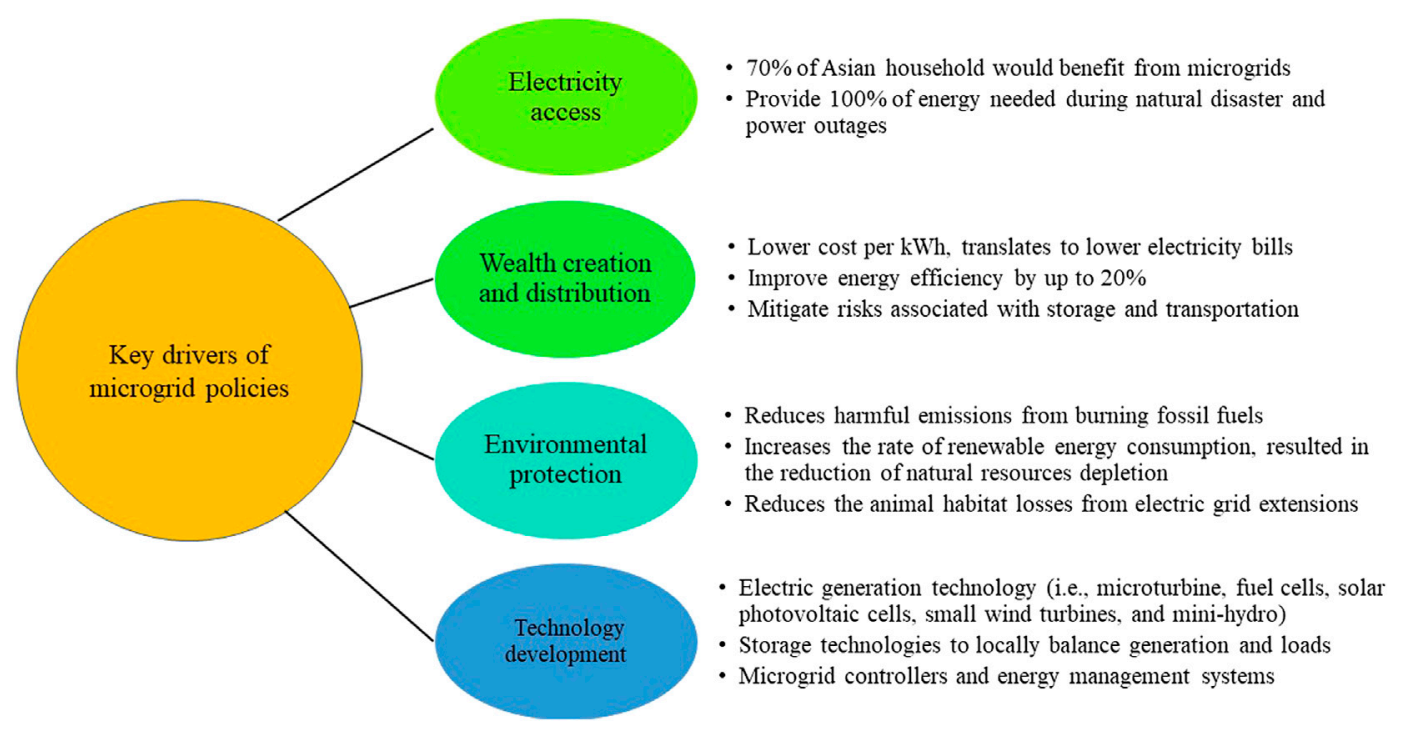

FIGURE 2 | Key drivers of microgrid policies.

example, electrical motors, refrigerators, microwave ovens, heaters, air conditioners, washing machines, computers, printers, entertainment sets, and telephones that consume electricity (Graber et al., 2018). Technologies of loads also move towards digital. Frequently, digital technology is smart and consumes less electricity. Many digital loads are likely to be sensitive to an electricity supply. Sensitive loads somewhat comprising electronic parts require high power quality of electricity. The modern, popular, and unique loads, EVs in particular, are not only dynamic in a conventional sense but are also movable (Anastasiadis et al., 2019; Mohammad et al., 2020). They can move and are free to move from one place to another within a short period of time. On special occasions, the moving of EVs results in increasing demands for electricity in specific areas, e.g., attractive tourism places and festival arrangement places. The batteries inside EVs have their dual roles of being charged and discharged. In other words, they can both consume electricity from an electricity grid and supply electricity to the electricity grid. This feature of EVs is well known as V2G. In short, electricity users not only need adequate electricity but also high power quality electricity for sensitive loads, including EVs. Another significant issue of EVs is the locations where the EVs consume and supply electricity. They may often change from one place to another. The microgrid design and development should take the technologies on the electricity user side into consideration.

\section{Review of Microgrid Policy}

An early step of microgrid development at an organizational or national level often starts with microgrid policies. In this study, the documented microgrid and smart grid policies were scrutinized. A review process covered the smart grid because the microgrid was considered as a subsystem of the smart grid (IEC, 2017). The reviewed literature showed key drivers of microgrid policies, the crucial motivations for developing microgrids. The key drivers were classified into four broad groups, i.e., 1) electricity access, 2) wealth creation and distribution, 3) environmental protection, and 4) technology development, shown in Figure 2.

\section{Electricity Access}

An electricity infrastructure has its interdependence with other critical infrastructures, e.g., water, food, oil/gas, healthcare, education, telecommunication, transportation, financial service, emergency service, and defense (Prehoda et al., 2017). Access to electricity is the global goal of many countries, especially economically developing countries. To some extent, electricity access fulfills the achievement of the United Nations Sustainable Development Goal of affordable and clean energy (IEA, IRENA, UNSD, WB, WHO, 2019). Microgrids can benefit the electricity access of people in several areas where 1) there is an existing main grid, 2) they are near the main grid, and even 3) they are far from the main grid (Bhagavathy and Pillai, 2018). However, review research on the national rural electrification plans of twenty countries showed that the integration of DG, a microgrid constituent, into electricity planning was slow (Ma and Urpelainen, 2018).

When the non-isolated microgrids take place inside or next to the main grid, they can be in the operation of either a gridconnected mode or an island mode. The non-isolated microgrids inside the main grid reinforce the main grid to have better power quality, reliability, safety, and efficiency to provide electricity to existing customers. Others next to the main grid expand the coverage of the main grid. They are a grid extension to provide electricity to new customers.

Isolated microgrids are established far from the main grid. People in a microgrid service area have their opportunity to consume electricity, maybe, for the first time in their life. The microgrids may improve power quality and the prolonged supply 
of electricity. People can therefore longer enjoy the pleasure of using electricity.

Microgrids have the potential to offer energy justice to people in various parts of society (Dolter and Boucher, 2018). Electricity users have their choices to get access to electricity at a reasonable price from their local grid, maybe from their neighbors. Microgrids are an opportunity to transform electricity prosumers, changing the electricity users' role from only consumption to both consumption and production.

\section{Wealth Creation and Distribution}

Microgrids require DERs and other resources. Stakeholders who produce and supply resources can increase their wealth (Biomass Research and Development Technical Advisory Committee, 2002; Barz, 2008). In the case of biomass and biogas energy resources, farmers have the choice to grow plants for energy, in addition to food, in order to optimize their incomes. Because of increasing microgrid development, demand for technologies of microgrid constituents has increased. This provides opportunities to manufacturers and suppliers of microgrid constituents. During a period of microgrid operation, microgrid operation and maintenance activities also lead to wealth creation and the distribution of wealth, e.g., microgrid manufacturers, suppliers, operators, and contractors. Apart from the aforementioned direct benefits, electricity from microgrids fundamentally provides further enormous opportunities to create and distribute wealth throughout a society (Khan et al., 2018; Ma and Urpelainen, 2018). From a utility perspective, the fundamental challenges of microgrid development are to increase overall sustained electricity supply quality, reliability, safety, and efficiency. Electricity users buy electricity at a reasonable price, and other stakeholders gain an acceptable return on their investment. In sum, the microgrid is one of the mechanisms of wealth creation and distribution in a society.

\section{Environmental Protection}

Energy production and distribution from renewable and nonrenewable DERs have, to some degree, impacts on the environment, economy, and society, no matter what (Zachar et al., 2015; Hong et al., 2018). Environmental concerns have been an interest of several international communities. $\mathrm{CO}_{2}$ emission reduction is one of the ways to realize these concerns (Zachar et al., 2015). In comparison with fossil fuels, renewable DERs of microgrid DGs reduce $\mathrm{CO}_{2}$ emission more (Parhizi et al., 2015; Mandal and Mandal, 2020). However, the information for analyzing the environmental costs and benefits of the economic multiplier is often less available, requiring more professional judgment by policymakers and regulators (Parag and Ainspan, 2019). Popular renewable energy candidates are, for example, solar, wind, mini-hydro, biomass, and biogas. Renewable energy promotion in energy policies responds to goals of clean energy, environmental protection, and $\mathrm{CO}_{2}$ emission reduction. Reducing $\mathrm{CO}_{2}$ emission and having a lower climate change impact, the microgrid needs both renewable DERs and a battery energy storage system (BESS) (Papageorgiou et al., 2020). In short, the aim of the microgrid policy is to protect the environment because of renewable energy promotion.

\section{Technology Development}

A modern smart microgrid has emerged because of the smart grid (IEC, 2017). The development of the smart grid is mainly based on the advancement of information and communication technologies. Technology development primarily aims at making things better by increasing various values, e.g., improving quality, efficiency, and flexibility, reducing costs, and preserving the environment. Technology development contributes to the feasibility of microgrid projects and policies. Microgrid policies in several countries were started with technology research, development, and demonstration activities (Hossain et al., 2014; Mariam et al., 2016; Hirsch et al., 2018). Other activities related to microgrid technology are valuable for scholars and practitioners, e.g., policymakers, professionals in electric utilities, and regulators.

\section{A CASE OF THAILAND MICROGRIDS}

The Thailand energy sector has evolved into a modern infrastructure, supporting several national social and economic activities as well as realizing environmental concerns. At a national level, renewable energy promotion has been in a Thailand energy development plan for more than a decade (EPPO, 2019e). The promotion aims at stabilizing the electrical energy supply, adding alternatives of renewable energy into the national energy mix. In addition, it leads to less dependence on fossil fuels - oil and gas.

The promotion of renewable energy has induced technological advancement in order to optimize the advantages and disadvantages of renewable energy. A smart grid and its sprout, a microgrid, have emerged as an integrated solution of the advanced technologies, especially those ICT-based technologies.

At a national level, the microgrid initiatives have been added to a Thailand energy development plan. At an organizational level, they also have been in the power system development plans of three Thailand state-owned electric utilities, namely electricity generating authority of thailand (EGAT), metropolitan electricity authority (MEA), and provincial electricity authority (PEA). In Thailand, a variety of microgrids have been developed by not only these three utilities, but also other stakeholders in the electricity supply industry, universities, and research institutes. In addition to the domestic entities, some foreign agencies have developed microgrid demonstration and pilot projects in Thailand.

\section{Four Types of Microgrids in Thailand}

Like many other countries, Thailand developed traditional microgrids in the early era of electrical power system development. Several smart microgrids with the advancement of microgrid technologies and policies have taken place in different locations in Thailand. Based on ownership and fund support, microgrids in Thailand can be divided into four groups: campus microgrids, utility microgrids, business microgrids, and 


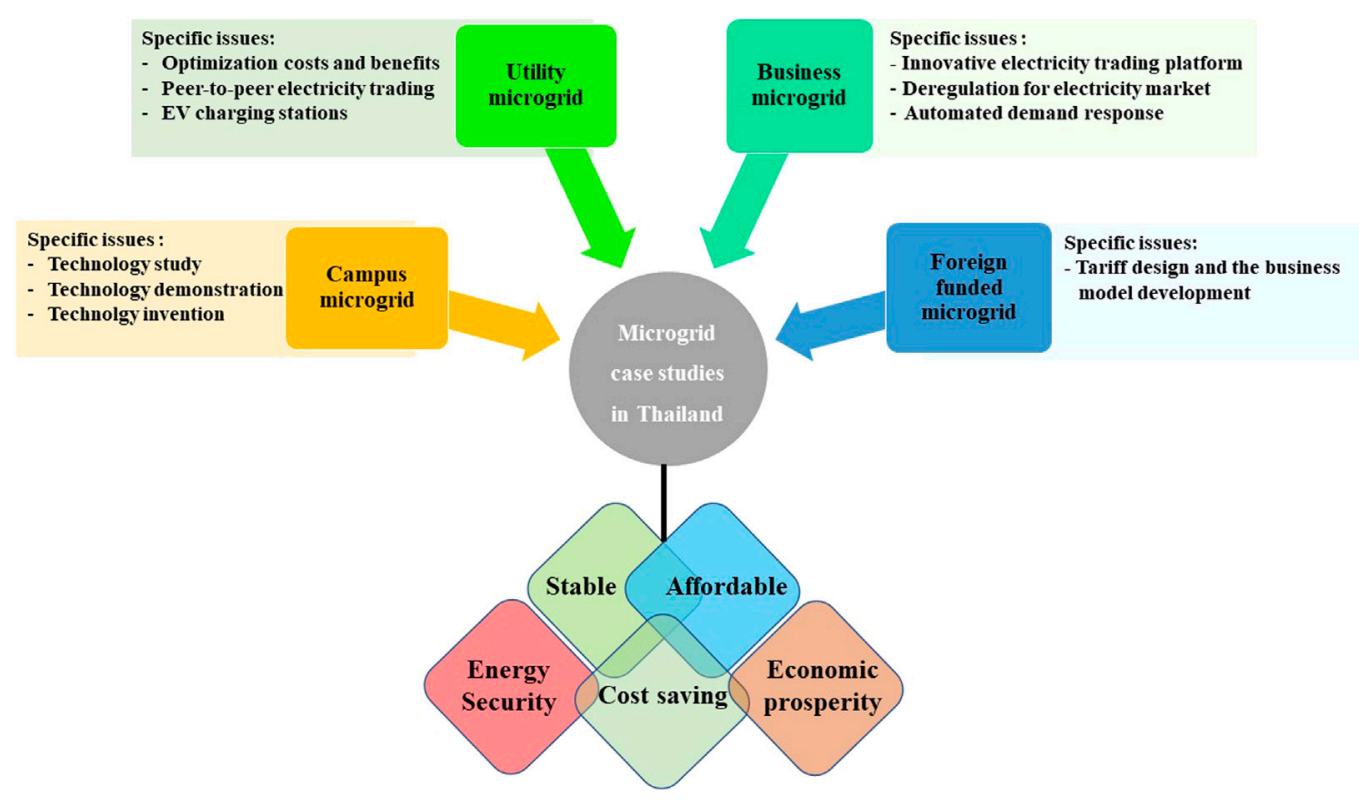

FIGURE 3 | Four types of microgrids in Thailand.

foreign-funded microgrids, shown in Figure 3. Each type of microgrid obtained various technical and non-technical data related to the motivation of Thailand microgrid development and deployed microgrid technologies in Thailand.

\section{Campus Microgrids}

Many universities in Thailand have carried out research and demonstration projects related to smart grids and/or microgrids. Those universities are, for example, the University of Phayao, Chiang Mai Rajabhat University, Naresuan University (NU), Chiang Mai University, Chulalongkorn University, King Mongkut's University of Technology Thonburi, and Kasetsart University (Thammasorn, 2014; CMU, 2017; Kerdphol et al., 2017; CMRU, 2019; KMUTT, 2019; University of Phayao, 2020).

DERs in the cases of Thailand campus microgrids comprised 1) renewable energy resources, i.e., solar photovoltaic (PV), biomass, biogas, and 2) non-renewable energy resources, i.e., diesel fuel. Both an AC grid and a DC grid were developed and investigated. Other developed microgrid constituents were, for example, a grid-tied type of PV rooftop and an EV charging station. Renewable energy resources, parts of a distributed generation unit, predominantly played significant roles in the development of campus microgrids. The concept of a smart city was deployed by four universities, i.e., the University of Phayao, Chiang Mai Rajabhat University, NU, and Chulalongkorn University, in order to extend a microgrid concept connecting with other campus community infrastructures.

The main purposes of the microgrid development of universities were based on technology, e.g., technology study, technology demonstration, and technology invention. The technology study and demonstration led to a body of knowledge assimilating into several microgrid-related courses of graduate schools. The technology invention mainly resulted in prototypes that were proof of concepts.

\section{Utility Microgrids}

All state-owned electric utilities in Thailand are in cooperation with an energy policymaking agency and an energy regulatory body. They made several microgrid development plans as research and development activities as well as pilot and demonstration projects (MOE, 2015; MOE, 2016).

EGAT issued a five-year microgrid demonstration plan which covered an area of the Mueang district of Mae Hong Son province (EPPO, 2019e). According to the plan, a microgrid was 1) a solar farm, 2) BESS, 3) DR mechanisms, 4) a micro energy management system, and 5) EVs and EV charging stations. This plan has been under implementation. Three other microgrid-related projects included two 37-MWh BESS installation plans, $16 \mathrm{MWh}$ in Chaiyapum province of the northeastern part of Thailand, and another $21 \mathrm{MWh}$ in Lopburi province in the northern part of Thailand. They were planned to support the penetration of distributed energy sources of wind and solar. Other grid-scale BESS might be additionally installed at the EGAT substations to cope with the coming of renewable distributed electricity generation. In addition, the Mae Mho smart city project, the EGAT demonstration, research, and development project in Lampang province, was in the plan. In the first quarter of 2019, EGAT developed an IT platform, namely a micro energy management system aimed at managing microgrids. Other microgrid development activities of EGAT are under planning.

MEA carried out the pilot urban microgrid project in the Samsen branch office in 2020. According to an MEA smart grid development plan, microgrids of MEA will be developed in four other locations including 1) the Praeksa area in Sumuthprakan 
province, 2) the suburban area of Nongjok district in Bangkok province, 3) a training and testing center in Pangplee district in Samuthprakan province, and 4) the Rat Burana branch office. Results of the feasibility study showed that the proposed microgrids in the first three locations were not financially feasible. Therefore, the microgrid at the Rat Burana branch office was designed. It comprised 1) $50 \mathrm{~kW}$ solar PV, 2) 30.7 and $500 \mathrm{~kW}$ BESS, 3) $160 \mathrm{kVA}$ diesel generator set, and 4) a microgrid controller (EPPO, 2019a).

PEA completed its microgrid at Khun Pae of the Chomtong district in Chiang Mai province in 2018, the first Thailand smart microgrid (EPPO, 2019d). It is an active on-grid microgrid supplying electricity to about 400 rural households. Two other microgrids, one in the Mae Sarieng district in Mae Hong Son province and another in the Betong district in Yala province, are under development (EPPO, 2019b; EPPO, 2019c). The cabinet resolution revealed the approval of the PEA proposed investment plan of the Koh Paluay microgrid project in Suratthani province (Royal Thai Government, 2020). Based on the Department of Alternative Energy Development and Efficiency's green energy projects, this microgrid will be on the Paluay island. Another PEA microgrid investment project in Suratthani province was the Koh Samui microgrid project, including the installation of the BESS in the existing electricity grid. This microgrid was designed by adding the BESS and Battery Management System into the existing electricity grid. In addition, PEA is transforming its traditional grid to a pilot smart grid project in Pattaya city in Chonburi province.

In order to gain insights for the increasing EV penetration, three electric utilities have adopted EVs and EV charging stations in their research and demonstration projects. In addition, they and NU have jointly carried out a research and development project related to peer-to-peer electricity trading within and among microgrids located in three electric utilitie's offices since 2019. According to the plan, the electricity trading platform would be tested in 2020 in a wholesale trading market using data of electricity trade between EGAT and MEA and between EGAT and PEA.

In addition to utility microgrids of three state-owned electric utilities, renewable DERs, especially solar PV and mini-hydro, were developed in several locations throughout Thailand by the Department of Alternative Energy Development and Efficiency and the Energy Planning and Policy Office under the Ministry of Energy. Those developed DGs would be parts of the electricity generation units of microgrids. Apart from the grid-connected microgrids, several isolated microgrids were developed in Chantaburi (Koh Jik project), Chiang Mai (Doi Intanon Royal project and Wat Chan Royal project), Sukothai (Kirimas project), Chachoeng Sau (Tha Takiab project), Uthai Thani (Huai Kha Khaeng project), and Chonburi (Koh Lan project) (Ngamroo, 2010).

Participants of utility microgrid development in the office completed the conceptual design and conducted the feasibility study. They preferred technologies that provided maximum benefit with a minimum cost of investment, operation, and maintenance. They carried out the optimization between the investment costs and the returned benefits.
Participants of utility microgrid development in the field reflected that practical aspects of microgrid technologies, i.e., installation, operation, and maintenance were their main criteria of technology selection. They preferred microgrid worker-friendly technologies. Managers and supervisors of microgrid field operation optimized the operation and maintenance costs. Automation and less maintenance microgrid technologies were also the preferences of people in the field.

Aims of utility microgrids were 1) to expand the electricity grid to new areas and customers, 2) to strengthen the existing electricity grid in terms of power quality, reliability, energy efficiency, and resiliency of electricity supply, and 3) to demonstrate and learn about microgrid technologies in several pilot projects. The utility microgrids are both grid-connected microgrids and isolated ones. Insights gained from the pilot projects were applied to shape or reshape the microgrid policies at the national level and the organizational level of the three utilities. In Thailand, the cooperation between utilities and universities was common in developing the utility microgrids. The university, a consultant, provided its insights and experiences gained from the implemented campus microgrid projects. As the microgrid technology buyers, three utilities took the foreign value-added content into account when they planned to import the foreign microgrid products and solutions. Other microgrids developed by government agencies were mainly aimed at demonstrating advanced microgrid technologies. In the latter case, the foreign content was not a big concern.

\section{Business Microgrids}

A domestic real estate development company, a domestic energy trading company, and an Australia-based technology startup company have tried out a peer-to-peer renewable electricity trading platform using blockchain since 2018 (World Economic Forum, 2018). Residents in a trial project located in Bangkok had the opportunity to buy and sell electricity between them. In the project, the total designed electricity generating capacity of solar PV panels was $635 \mathrm{~kW}$ which would be traded via an electricity grid between a mall, a school, a dental hospital, and an apartment complex. After a trial period, the alliance of three companies, energy policymakers, and energy regulators found challenges in creating energy policies and legal regulations that were more suitable for the innovative electricity trading platform. The alliance reflected that deregulation was an obvious requirement of private investors in an electricity market. Deregulation should be, at least, allowed for a trial period. In doing so, the Energy Regulatory Commission of Thailand launched a sandbox project and invited those who were interested in creating innovations in energy activities, including energy trading. The sandbox initiative was expected by the regulator to bring about new concepts of technologies and regulations.

\section{Foreign-Funded Microgrids}

The $1.21 \mathrm{~km}^{2}$ Koh Jik island in Chantaburi province has 98 households and 400 residents. Funded by a group of Australian activists, namely Australian Aid, an existing 
microgrid on the Koh Jik island has been renovated by a team of Thais and foreigners. The renovation work included the installation of new solar PV panels, Li-ion batteries, smart meters, and an automatic control system or a microgrid controller (Koh Jik Recharge, 2019). An existing $50 \mathrm{~kW}$ diesel generator was a backup generation unit in a case of lack of electricity supply from renewable energy resources. According to the renovation plan, a new generator together with an autostart function would replace the existing diesel generator. In addition to the technical parts of microgrids, the initiated activities include the tariff design and the business model development. The project developers have tried to persuade the Thailand energy regulator to permit them to implement the developed business model.

The techno-economic analysis of this microgrid case appeared in the Koh Jik project. The lowest cost of electricity combined with the highest renewable fraction can be as low as $0.220 € / \mathrm{kWh}$ with the project payback of 6.3 years (IRR 15.28\%) (Veilleux et al., 2020).

In addition to the abovementioned foreign-funded microgrid, the New Energy and Industrial Technology Organization of Japan and Japanese companies cooperated with the Thailand government agencies to build microgrids in three locations, i.e., 1) the NU energy park in the northern region of Thailand, 2) the rice milling plant, and 3) three national parks (Phu Kradueng, Huai Kha Khaeng, and Tarutao Island) (Ngamroo, 2010).

\section{Microgrid Technologies in Thailand}

Technologies of microgrids refer to technologies of distributed generation units, electricity distribution systems, electricity users, and protection and control units. It is worth noting that a majority of the organizational entity in Thailand, in general, are a microgrid technology buyer, user, and importer. Their main activities include technology verification, technology adoption, and system integration, integrating microgrid equipment into a microgrid.

\section{Technologies of a Distributed Generation Unit}

In Thailand, DG units, typically known as Very Small Power Producers (VSPP), had a capacity of no more than $10 \mathrm{MW}$. They used both renewable and non-renewable energy. Technologies of renewable DG units were concerned with solar, wind, biomass, biogas, and mini-hydro. The non-renewable DG units were diesel engines and gas engines. The majority of technologies were diesel engines, solar PV, and biomass (Ngamroo, 2010; DEDE, 2015). In addition, a microgrid DG unit used battery energy storage in many Thailand microgrid cases.

A diesel engine, a firm electricity source, had its strength in the performance maturity and availability of diesel fuel. The diesel engine was in operation when there was no sunlight and wind, or there was not enough electricity produced from renewable energy sources. There were several brands and suppliers of diesel engines, originating from many foreign countries. Technical supports and services related to diesel engines were locally available. Local technicians had the skills to carry out the operation and maintenance of diesel engines.
The popularity and price tendency of solar PV in a world market had effects on the selection and promotion of clean energy technology in a Thailand electricity market. The proven potential of solar radiation in Thailand was prevalent. Therefore, solar PV was a constituent of every microgrid case in Thailand.

Apart from its renewable energy, solar PV was a symbol of clean energy in Thailand. Four popular types of PV panels, i.e., monocrystalline, polycrystalline, thin-film/amorphous silicon, and concentrated PV, were deployed in Thailand microgrid projects. Various types of inverter, e.g., grid-tied, standalone, string/central, and micro, were observed. Like those of diesel engines, technical supports, service, and operation and maintenance skills of technicians were commonly available throughout Thailand.

Thailand, an agricultural country, has a myriad of biomass energy potential for satisfying the country's electricity requirements. Biomass in two energy forms, i.e., electricity and heat, played a significant role in the Thailand energy market. Various sources of biomass include, for example, rice husk and straw; cane leaves, top, and bagasse; corn leaves, cob, and stalk; palm fiber, and shell; cassava roots; leaves and stems of bean plants; and wood chips, sawdust, shavings, slabs, and branches of many planted trees, e.g., rubber and eucalyptus. A total of $2,451.82 \mathrm{MW}$ of electricity was generated from biomass in 2014 which should increase to $5,570.00 \mathrm{MW}$ or by $127.18 \%$ by 2036 (DEDE, 2015). The human resource capabilities to deal with biomass in Thailand were strong because of agricultural practices of developing, harvesting, and processing biomass resources. Technologies conversing biomass to electricity include cofiring, direct combustion, and biomass gasification. Even though there were several biomass power plants of VSPPs, they played small roles in Thailand microgrid projects. Wherever the biomass power plants of VSPPs existed, PEA added it in a conceptual design process as a microgrid constituent of an electricity generation.

\section{Technologies of an Electricity Distribution System}

In the Thailand microgrid cases, some technologies of electricity distribution systems, e.g., pole, wire, and transformer, were conventional. Others, e.g., relay, fault detection, and meter, were newly invented or upgraded to be digital. Most Thailand microgrids, excluding one of PEA in Mae Hong Son province, were low voltage AC. The PEA microgrid in Mae Hong Son province was medium voltage AC (EPPO, 2019c). It was a microgrid at a substation level. Radio frequency-based and wireless communication technologies, including cellular technology, were applied in developing Thailand microgrids. Manufacturers in Thailand could produce poles, wires, and transformers. Others were imported technologies. In addition to manufacturing capabilities, human resource skills to design, plan, install, operate, and maintain the microgrid electricity distribution system already took place in Thailand.

\section{Technologies of a Protection and Control Unit}

The revolution of protection and control technologies in the electric power system reflected the extent to which the electric power system became modernized in the sense of being reliable, 
monitored, controlled, and resilient. Technologies of the protection and control unit in Thailand microgrids varied from traditional ones without the embedded ICT to ICTintegrated versions. They, for example, consisted of fuses, circuit breakers, relays, reclosers, and disconnecting switches. In the case of the Thailand utility microgrids, microgrid operators could remotely control circuit breakers, relays, and disconnecting switches. Relays deployed in Thailand microgrids were digital. The relay, the circuit breaker, and the recloser were imported technologies; other protection and control equipment were products of Thailand domestic manufacturers. In Mae Hong Son province, PEA applied the IEC61850 standard of the smart substation to build the microgrid. This evidence, to some degree, showed that Thailand contained human resource capabilities to carry out design, planning, installation, operation, and maintenance of the microgrid protection and control units.

\section{Technologies of Electrical Load}

In the Thailand microgrids, there were two broad groups of electricity users, a rural group and a city group. In the rural group, the electrical loads of households were rice cookers, mobile phones, fans, radio sets, and television sets. Refrigerators and air conditioners were in some rural households. In the city group, all electrical devices in the rural group could be found in the city group. The refrigerators and the air conditioners were common in the city group. In addition, modern electrical devices, e.g., electric vehicles, battery packs, clothes washing machines, and dishwashing machines, electric ovens, and microwave ovens, were the microgrid electrical loads in the city group. Apart from the microgrid electrical loads of households in the city group, there were several electrical loads of business microgrids, including a mall, a school, and a dental hospital. There were many brands and sellers of electrical devices. Service after sale might include installation, user handbooks, and maintenance. In Thailand, there was, in general, no special need for foreign human resource capabilities to deal with electrical loads.

\section{Thailand Microgrid Policy}

The microgrid policies in Thailand were at an organizational level and a national level. At the organizational level, they were related to campus microgrids, business microgrids, and foreign-funded microgrids. Not only at the organizational level but at the national level as well, the policies were relevant to the utility microgrids.

All Thailand microgrid cases to some extent added contributions to technology development and environmental protection. In addition, the utility microgrid cases added contributions to electricity access and wealth creation and distribution. From an aspect of wealth creation and distribution, the business microgrid case focused on the financial return of owners, especially those of business microgrids. In addition to the general contributions to the environment, environmental protection shaped the good image of the business microgrid owner in particular.

At the national level, the microgrid development was a public policy in the Thailand electric power system development plan in 2018 (EPPO, 2019e). The utility microgrids, especially of two state-owned enterprises of MEA and PEA, were planned to achieve all four broad groups of key drivers. In addition, they were designed to improve various technical aspects of the electric power system, i.e., power quality, reliability, resiliency, energy efficiency, and safety. From a technical aspect, it was closely related to the development of a smart grid. The public microgrid policies were aimed at fulfilling demands for electricity access, wealth creation and distribution, environmental protection, and technology development. Because of their spatial characteristics, renewable energy resources played critical roles in microgrid policies of electricity access, wealth creation and distribution, environmental protection, and technology development.

The microgrid policies of electricity access had the target area in both urban and rural areas. In the urban areas, they were formulated because of the existing and planned renewable distributed generation. In rural areas, they were set because of a lack of electricity, low reliability, low power quality, and the local potential of renewable resources in those areas. The rural areas included the remote areas in an agricultural sector, islands, mountainous areas, protected areas, marginalized rural areas, and environmentally sensitive areas.

The promotion of renewable energy resources based on local potential included solar, wind, mini-hydro, and biomass. Biomass resources can not only produce electricity but also enable new economic growth to create and distribute wealth among a majority of Thai people, especially in the agricultural sector. The Thailand government attempted to promote small biomass-based community power plants that induced demands for agricultural residuals, the power plants' raw materials (EPPO, 2020). The ecosystem of biomass energy covered both the electrical energy sector and the agricultural sector.

\section{DISCUSSION AND RECOMMENDATIONS}

Collected data of Thailand microgrid cases in Section A Case of Thailand Microgrids revealed findings related to microgrid technologies and key drivers of Thailand microgrid policies. Discussions and recommendations about the technologies and drivers are in Sections Technology of Thailand Microgrid Case and Key Driver of Thailand Microgrid Policy.

\section{Technology of Thailand Microgrid Case}

In general, Thailand is a country of microgrid technology buyers, users, and importers, rather than sellers, producers, and exporters. This Thailand microgrid technology position is crucial when seting microgrid policies. It reveals activities of short-term and long-term microgrid development. Table 1 shows the findings related to microgrid technologies from the case of Thailand microgrids.

In the technology domain of the microgrid distributed generation unit, Thailand has, to some extent, the technological capabilities of preparing biomass resources and manufacturing PV panels. However, many PV panels have been imported from different countries, e.g., Germany, Japan, and China. Two factors, i.e., imported content of microgrid technologies and technology suppliers, are significant for policymakers when setting the microgrid policies. 
TABLE 1 | Findings related to microgrid technologies from a case of Thailand microgrids.

\section{Microgrid case}

Campus microgrid

Utility microgrid

Business microgrid

Foreign-funded microgrid
Finding related to technologies in microgrid policies

Academic knowledge, technology demonstration

Practical knowledge, imported content of microgrid technologies, cost of microgrid technologies, human resource capabilities to deal with microgrid technologies, microgrid technology suppliers

Practical and investment knowledge, technology showcase

Academic knowledge, real experiment of technology
In the other technology domains of microgrid constituents, especially the electricity distribution system, Thailand has the capability to design, produce, install, operate, and maintain the technologies. However, foreign countries often supply several advanced technologies of microgrid constituents. Most protection and control technologies, in particular, are also imported from other countries. In short, Thailand has some capabilities to produce simple microgrid technologies.

On the one hand, the academic knowledge for teaching and learning about microgrid technologies is crucial in the campus microgrid cases and the foreign-funded microgrid cases. On the other hand, the practical knowledge for dealing with microgrid technologies, e.g., planning, design, installation, operation, and maintenance, is significant in the utility microgrid cases. In a business microgrid case, microgrid technologies are the showcase of microgrid products, solutions, and services from suppliers. Because of the advanced features of business microgrids, the business microgrid technologies stimulate, somewhat, the trust of investors in the business microgrid case.

The case of Thailand microgrids is unique on a the microgrid technology demand side which is different from those cases on a microgrid technology supply side (Romankiewicz et al., 2014; Ali et al., 2017). Four interests of technology supply as mentioned in Romankiewicz et al. (2014) (i.e., new market, new products, innovation, and profit) are not an outstanding issue in the case of Thailand microgrids. In setting microgrid policies, the case of Thailand microgrids provides more dimensions about microgrid technologies than those stated in Ali et al. (2017). The development of microgrids in Thailand has also faced several technical challenges (e.g., reconnection of the gridconnected microgrid to the main utility grid after a fault, and development of a robust control and protection system) as mentioned in Choudhury (2020).

\section{Key Driver of Thailand Microgrid Policy}

The emerging smart grid concept, the advancement of information and communication technology, and the promotion of renewable energy provoke a new concept of microgrids (Choudhury, 2020). In Thailand, the microgrid is a public policy instrument of electricity access, especially in sensitive areas, e.g., remote rural areas, marginalized rural areas, islands, and mountainous areas. The Thailand microgrids mainly react to distributed generation that generally results from renewable DERs. Renewable DERs play a significant role in both distributed generation units and the perception of electricity users on an electrical load side. The promotion of renewable energy leads not only to distributed generation, one of the microgrid constituents, but also environmental protection. In other words, renewable energy resources make microgrids environmentally friendly. The utility microgrids, a majority of Thailand microgrid cases, are driven by public policy and the legal flexibility to benefit the microgrid development. Like several cases in other countries, the Thailand microgrid cases reveal four key drivers, i.e., 1) electricity access, including the technical improvement of power quality, reliability, energy efficiency, and resiliency of electricity supply, 2) wealth creation and distribution, especially via the development of the very small biomass power plant, 3) environmental protection, related to the promotion of renewable energy to reduce $\mathrm{CO}_{2}$ emission and to fulfill the access to electricity toward the United Nations Sustainable Development Goal of affordable and clean energy, and 4) technology development as a technology buyer, importer, and user (Bhagavathy and Pillai, 2018; Ma and Urpelainen, 2018; IEA, IRENA, UNSD, WB, WHO, 2019; Parag and Ainspan, 2019; Pullins, 2019; Mandal and Mandal, 2020). An individual Thailand microgrid reveals some key drivers, rather than all key drivers. Overall, four key drivers emerge after taking all microgrids into account. Table 2 shows findings related to the key drivers of each Thailand microgrid case.

The utility microgrids in Thailand, strongly influenced by the microgrid public policies, aimed at thriving electricity access, wealth creation and distribution, environmental protection, and technology development. The first three drivers of microgrid development in Thailand, excluding technology development, are of energy security and low energy cost; economic growth; climate change mitigation, clean energy, and clean air that were stated in Romankiewicz et al. (2014). With all four drivers, the utility microgrids in Thailand proved that utility was the large contributor of microgrid development (Choudhury, 2020). In addition, a case of Thailand microgrids is likely to be a consequence of the feasible microgrid policies, proposing the microgrid as an emerging very small electricity grid. In contrast to the study of Ali et al. (2017), this seems to be a situation of accelerating microgrid implementation.

\section{Recommendations for Academia and Practitioners}

Recommendations for academia are related to the knowledge creation and transfer of microgrid technologies. The action research intended to solve real-world problems, like the case of the PEA Khun Pae microgrid, is also recommended. In Thailand, 
TABLE 2 | Findings related to key drivers of Thailand microgrids.

\section{Microgrid case}

Campus microgrid

Utility microgrid

Business microgrid

Foreign-funded microgrid
Finding related to key drivers of Thailand microgrids

Environmental protection, technology development

Environmental protection, technology development, wealth creation and distribution, electricity access Environmental protection, technology development, wealth creation and distribution Environmental protection, technology development there is great potential to research microgrid biomass technologies. In addition to direct technology-related interests, the evaluation of new microgrid initiatives and how the appraisal of microgrids impacts various stakeholders, society, and the environment are valuable to research. In addition, the evidence of microgrid performance is recommended to be collected and analyzed.

Recommendations for practitioners, i.e., policymakers, regulators, and professionals in state-owned enterprises, are related to the added value of microgrid technologies. The recommended issues for public policy formulation are the import content of microgrid technologies which are sensitive to the costs and benefits of microgrid projects, the availability of microgrid technology supply, the wealth distribution among microgrid stakeholders, and the sustainability of microgrids in terms of economy and environment.

\section{CONCLUSION}

This research explores and investigates four types of microgrids in Thailand, i.e., a campus microgrid, a utility microgrid, a business microgrid, and a foreign-funded microgrid. A case study approach had been applied in this research. First hand and secondary data were collected and analyzed. Findings show four microgrid constituents (i.e., a distributed generation unit, an electricity distribution system, a protection and control unit, and an electrical load) and their related technologies. Four popular renewable energy resources in the distributed generation unit in Thailand are solar, wind, biomass, and mini-hydro. The planning, design, installation, operation, and maintenance of microgrid technology are required for microgrid development. Human resource capabilities to deal with microgrid technology utilization are significant. As a microgrid technology buyer, user, and importer, Thailand has, to some extent, these human resource capabilities to integrate, design, plan, install,

\section{REFERENCES}

Ali, A., Li, W., Hussain, R., He, X., Williams, B. W., and Memon, A. H. (2017). Overview of current microgrid policies, incentives and barriers in the European Union, United States and China. Sustain 9, 1146. doi:10.3390/su9071146

Anastasiadis, A. G., Kondylis, G. P., Polyzakis, A., and Vokas, G. (2019). Effects of increased electric vehicles into a distribution network. Energy Proced. 157, 586-593. doi:10.1016/j.egypro.2018.11.223

Bani-Ahmed, A., Weber, L., Nasiri, A., and Hosseini, H. (2014). "Microgrid communications: state of the art and future trends," in 3rd international conference on renewable energy research and applications, ICRERA 2014, operate, and maintain microgrid technologies. The majority of Thailand microgrids are driven by public policy and legal flexibility. The key drivers of Thailand microgrid policies are 1) electricity access, 2) wealth creation and distribution, 3) environmental protection, and 4) technology development. Like those in the US (C2ES Solutions Forum, 2017), rural and urban microgrids in Thailand are expected to grow in the future. As shown in the Thailand microgrid cases, the advancement of peer-to-peer (P2P) trading and blockchain will drive the commercialization of microgrid projects in urban areas. Meanwhile, the need for reliable and resilient power supply in remote rural areas will drive microgrid market growth in Thailand. However, the challenges in the deregulation of the electricity supply industry and political support are likely to slow down Thailand microgrid market growth. Findings from and recommendations for Thailand microgrid cases are expected to be taken into consideration and verified in other similar contexts.

\section{AUTHOR CONTRIBUTIONS}

TM designed the research process, collected and analyzed the research data, and wrote the paper. PU provided suggestions and recommendation for conducting the research and revised the paper.

\section{ACKNOWLEDGMENTS}

The authors would like to thank 1) Rattanakosin College for Sustainable Energy and Environment, Rajamangala, University of Technology Rattanakosin, and 2) Provincial Electricity Authority. The authors also gratefully acknowledge the data provided from a database and personnel of 1) the Energy Policy and Planning Office, the Ministry of Energy, and 2) the Energy Regulatory Commission.

Milwaukee, WI, October 19, 2014, 780-785. doi:10.1109/ICRERA.2014. 7016491

Barz, M. (2008). Biomass technology for electricity generation in community. Int. J. Renew. Energy 3, 1-10.

Bhagavathy, S. M., and Pillai, G. (2018). PV microgrid design for rural electrification. Designs 2, 1-22. doi:10.3390/designs2030033

Biomass Research and Development Technical Advisory Committee (2002). Roadmap for biomass technologies in the United States. Washington, DC: ASM Press.

Bo, Z. Q., Lin, X. N., Wang, Q. P., Yi, Y. H., and Zhou, F. Q. (2016). Developments of power system protection and control. Prot. Control Mod. Power Syst. 1, 7. doi:10.1186/s41601-016-0012-2 
Bullich-Massagué, E., Díaz-González, F., Aragüés-Peñalba, M., Girbau-Llistuella, F., Olivella-Rosell, P., and Sumper, A. (2018). Microgrid clustering architectures. Appl. Energy 212, 340-361. doi:10.1016/j.apenergy.2017.12.048

C2ES Solutions Forum (2017). Key insights for expanding microgrid development. Washington, DC: IEEE, 1-3.

Choudhury, S. (2020). A comprehensive review on issues, investigations, control and protection trends, technical challenges and future directions for Microgrid technology. Int. Trans. Electr. Energy Syst. 30, 1-16. doi:10.1002/2050-7038. 12446

CMRU (2019). Overview: Asian development college for community economy and technology. Asian dev. coll. community econ. technol. (adiCET), Chiang Mai Rajabhat Univ. Available at: https://www.adicet.cmru.ac.th/web2019/overview2/ (Accessed July 26, 2020).

CMU (2017). CMU smart city-clean energy Chiangmai Univ. Available at: https:// prcmu.cmu.ac.th/scoop_detail.php?sco_sub_id=2167 (Accessed July 25, 2020)

DEDE (2015). Alternative energy development plan (AEDP2015), Bangkok. Available at: http://www.eppo.go.th/index.php/en/policy-and-plan/en-tieb/ tieb-aedp.

Dewadasa, M., Majumder, R., Ghosh, A., and Ledwich, G. (2009). "Control and protection of a microgrid with converter interfaced micro sources," in 2009 International conference on power systems ICPS '09, Kharagpur, India, December 27-29, 2009, 25-30. doi:10.1109/ICPWS.2009.5442654

Dolter, B. D., and Boucher, M. (2018). Solar energy justice: a case-study analysis of Saskatchewan, Canada. Appl. Energy 225, 221-232. doi:10.1016/j.apenergy. 2018.04.088

EPPO (2019a). 2019 Progress report on the MEA smart grid (Microgrid \& ESS) implementation. Available at: https://thai-smartgrid.com/wp-content/uploads/ 2020/02/3-4-เสาหลักที่-3-MEA-03-V3.4-Final.pdf.

EPPO (2019b). 2019 Progress report on the PEA smart grid (Microgrid \& ESS) implementation: the Betong Microgrid, Bangkok. Available at: https://thaismartgrid.com/wp-content/uploads/2020/02/3-5-เสาหลักที่-3-PEA-02-V3.4Final.pdf.

EPPO (2019c). 2019 Progress report on the PEA smart grid (Microgrid \& ESS) implementation: the Mae Sarieng Microgrid, Bangkok. Available at: https:// thai-smartgrid.com/wp-content/uploads/2020/02/3-6-เสาหลักที่-3-PEA-03-1V3.4-Final.pdf.

EPPO (2019d). 2019 Progress report on the PEA smart grid (Microgrid \& ESS) implementation: the khun pae Microgrid, Bangkok. Available at: https://thaismartgrid.com/wp-content/uploads/2020/02/3-9-เสาหลักที่-3-PEA-MGขุนแปะ-V3.4-Final.pdf.

EPPO (2020). Resolution of the national energy policy committee. Energy policy plan. Off. Available at: http://www.eppo.go.th/index.php/th/component/k2/ item/16363-news-181163 (Accessed November 30, 2020).

EPPO (2019e). Thailand power development plan 2018-2037 (PDP2018) Bangkok. Available at: http://www.eppo.go.th/images/POLICY/PDF/PDP2018.pdf.

Feijoo, F., and Das, T. K. (2015). Emissions control via carbon policies and microgrid generation: a bilevel model and pareto analysis. Energy 90, 1545-1555. doi:10.1016/j.energy.2015.06.110

Feng, W., Jin, M., Liu, X., Bao, Y., Marnay, C., Yao, C., et al. (2018). A review of microgrid development in the United States-a decade of progress on policies, demonstrations, controls, and software tools. Appl. Energy 228, 1656-1668. doi:10.1016/j.apenergy.2018.06.096

Graber, S., Narayanan, T., Alfaro, J., and Palit, D. (2018). Solar microgrids in rural India: consumers willingness to pay for attributes of electricity. Energy Sustain. Dev. 42, 32-43. doi:10.1016/j.esd.2017.10.002

Hirsch, A., Parag, Y., and Guerrero, J. (2018). Microgrids: a review of technologies, key drivers, and outstanding issues. Renew. Sustain. Energy Rev. 90, 402-411. doi:10.1016/j.rser.2018.03.040

Hong, B., Zhang, W., Zhou, Y., Chen, J., Xiang, Y., and Mu, Y. (2018). EnergyInternet-oriented microgrid energy management system architecture and its application in China. Appl. Energy 228, 2153-2164. doi:10.1016/j.apenergy. 2018.07.081

Hossain, E., Kabalci, E., Bayindir, R., and Perez, R. (2014). Microgrid testbeds around the world: state of art. Energy Convers. Manag. 86, 132-153. doi:10. 1016/j.enconman.2014.05.012

IEA, IRENA, UNSD, WB, WHO (2019). Tracking SDG 7: the energy progress report 2019 Washington DC. Available at: https://www.irena.org/publications/ 2019/May/Tracking-SDG7-The-Energy-Progress-Report-2019.
IEC (2017). IEC TS 62898-1 Microgrids-Part 1: guidelines for microgrid projects planning and specification. IEC. Available at: https://webstore.iec.ch/preview/ info_iec62898-1\%7Bed1.0\%7Den.pdf.

IEC (2014). White Paper: Microgrids for disaster preparedness and recovery. with electricity continuity plans and systems, Geneva, Switzerland: IEC, 41-45(.)

Intel (2020). Intel microgrid technology is transforming the energy grid. Available at: $\quad$ https://www.intel.com/content/www/us/en/energy/microgrid.html (Accessed..October 31, 2020).

Iqbal, Z., Javaid, N., Iqbal, S., Aslam, S., Khan, Z., Abdul, W., et al. (2018). A domestic microgrid with optimized home energy management system. Energies 11, 1002. doi:10.3390/en11041002

IRENA (2019). Future role of Distribution system operators. United Arab Emirates: International Renewable Energy Agency, 1-20(.)

Kerdphol, T., Rahman, F. S., Mitani, Y., Hongesombut, K., and Küfeoğlu, S. (2017). Virtual inertia control-based model predictive control for microgrid frequency stabilization considering high renewable energy integration. Sustain 9, 773. doi:10.3390/su9050773

Khan, H. A., Ahmad, H. F., Nasir, M., Nadeem, M. F., and Zaffar, N. A. (2018). Decentralised electric power delivery for rural electrification in Pakistan. Energy Policy 120, 312-323. doi:10.1016/j.enpol.2018.05.054

KMUTT (2019). Thailand energy award 2019 King Mongkut's. Univ. Technol. Thonburi. Available at: https://pr.kmutt.ac.th/pr2/wp-content/uploads/2019/ 10/62-10-18C.pdf (Accessed July 26, 2020).

Koh Jik Recharge (2019). The future energy show. Kho Jik recharg., 1-30. Available at: https://www.rechargethailand.com/downloads (Accessed July 27, 2020).

Kumar, J., Agarwal, A., and Agarwal, V. (2019). A review on overall control of DC microgrids. J. Energy Storage 21, 113-138. doi:10.1016/j.est.2018.11.013

Liu, C. (2019). A review of microgrid development and technology. IOP Conf. Ser. Earth Environ. Sci. 300, 042048. doi:10.1088/1755-1315/300/4/042048

LO3 Team (2018). All about microgrids. LO3 energy. Available at: http://lo3energy. com/find-energy-industry-needs-microgrids-work-now-work-future/ (Accessed July 15,2020 ).

Ma, S., and Urpelainen, J. (2018). Distributed power generation in national rural electrification plans: An international and comparative evaluation. Energy Res. Soc. Sci. 44, 1-5. doi:10.1016/j.erss.2018.04.002

Mandal, S., and Mandal, K. K. (2020). Optimal energy management of microgrids under environmental constraints using chaos enhanced differential evolution. Renew. Energy Focus. 34, 129-141. doi:10.1016/j.ref.2020.05.002

Mariam, L., Basu, M., and Conlon, M. F. (2016). Microgrid: architecture, policy and future trends. Renew. Sustain. Energy Rev. 64, 477-489. doi:10.1016/j.rser.2016. 06.037

MOE (2016). Thailand smart grid action plan. Bangkok. Available at: http://www. eppo.go.th/images/Power/pdf/smart_grid_actionplan.pdf.

MOE (2015). Thailand smart grid master plan. Bangkok. Available at: http://www. eppo.go.th/images/Power/pdf/smart_gridplan.pdf.

Mohammad, A., Zamora, R., and Lie, T. T. (2020). Integration of electric vehicles in the distribution network: a review of PV based electric vehicle modelling. Energies 13, 4541. doi:10.3390/en13174541

Ngamroo, I. (2010). Status of microgrid R \& D in Thailand Vancouver, BC, Canada. Available at: https://microgrid-symposiums.org/wp-content/uploads/ 2014/12/vancouver_ngamroo.pdf.

Pachanapan, P. (2018). Islanding management of microgrid with multi-renewable energy sources. GMSARN Int. J. 12, 47-55.

Papageorgiou, A., Ashok, A., Hashemi Farzad, T., and Sundberg, C. (2020). Climate change impact of integrating a solar microgrid system into the Swedish electricity grid. Appl. Energy. 268, 114981. doi:10.1016/j.apenergy. 2020.114981

Parag, Y., and Ainspan, M. (2019). Sustainable microgrids: economic, environmental and social costs and benefits of microgrid deployment. Energy Sustain. Dev. 52, 72-81. doi:10.1016/j.esd.2019.07.003

Parhizi, S., Lotfi, H., Khodaei, A., and Bahramirad, S. (2015). State of the art in research on microgrids: a review. IEEE Access 3, 890-925. doi:10.1109/ACCESS. 2015.2443119

Prehoda, E. W., Schelly, C., and Pearce, J. M. (2017). U.S. strategic solar photovoltaicpowered microgrid deployment for enhanced national security. Renew. Sustain. Energy Rev. 78, 167-175. doi:10.1016/j.rser.2017.04.094

Pullins, S. (2019). Why microgrids are becoming an important part of the energy infrastructure. Electr. J. 32, 17-21. doi:10.1016/j.tej.2019.05.003 
Reilly, J. T. (2019). From microgrids to aggregators of distributed energy resources. The microgrid controller and distributed energy management systems. Electr. J. 32, 30-34. doi:10.1016/j.tej.2019.05.007

Romankiewicz, J., Marnay, C., Zhou, N., and Qu, M. (2014). Lessons from international experience for China's microgrid demonstration program. Energy Policy 67, 198-208. doi:10.1016/j.enpol.2013.11.059

Royal Thai Government (2020). Cabinet resolution on July 21, 2020. R. Thai Gov. Available at: https://www.thaigov.go.th/news/contents/details/33560 (Accessed November 28, 2020).

Shukla, S., Deng, Y., Shukla, S., and Mili, L. (2014). "Construction of a microgrid communication network," in 2014 IEEE PES innovative smart grid technologies conference ISGT2014, Washington, DC, February 19-22, 2014. doi:10.1109/ ISGT.2014.6816412

Thammasorn, C. (2014). Generation unit commitment in microgrid with renewable energy generation combined heat and power and energy storage system. Thailand: Chulalongkorn University.

University of Phayao (2020). UP energy and climate change. Univ. Phayao. Available at: http://www.sustainability.up.ac.th/G_Energy_Cilmate.aspx (Accessed July 25, 2020).

Veilleux, G., Potisat, T., Pezim, D., Ribback, C., Ling, J., Krysztofiński, A., et al. (2020). Techno-economic analysis of microgrid projects for rural electrification: a systematic approach to the redesign of Koh Jik off-grid case study. Energy Sustain. Dev. 54, 1-13. doi:10.1016/j.esd.2019.09.007

Wang, C., Yan, J., Marnay, C., Djilali, N., Dahlquist, E., Wu, J., et al. (2018). Distributed energy and microgrids (DEM). Appl. Energy 210, 685-689. doi:10. 1016/j.apenergy.2017.11.059
Warwick, W., Hardy, T., Hoffman, M., and Homer, J. (2016). Electricity distribution system baseline report. Available at: https://www.energy.gov/ sites/prod/files/2017/01/f34/Electricity Distribution System Baseline Report.pdf World Economic Forum (2018). In this Bangkok neighbourhood, you can buy and sell electricity using Blockchain. Available at: https:/www.weforum.org/ agenda/2018/08/in-a-posh-bangkok-neighbourhood-residents-trade-energywith-blockchain (Accessed July 27, 2020)

Yarali, A., and Rahman, S. (2012). "Wireless communication for smart grids," in Second international conference on advanced collaborative networks, systems and applications 2012 (COLLA 2012), Venice, Italy, June 24-29, 2012, 1-9(.) Yin, R. K. (2018). Case study research and applications. Los Angeles: Sage.

Zachar, M., Trifkovic, M., and Daoutidis, P. (2015). Policy effects on microgrid economics, technology selection, and environmental impact. Comput. Chem. Eng. 81, 364-375. doi:10.1016/j.compchemeng.2015.03.012

Conflict of Interest: The authors declare that the research was conducted in the absence of any commercial or financial relationships that could be construed as a potential conflict of interest.

Copyright (c) 2021 Meenual and Usapein. This is an open-access article distributed under the terms of the Creative Commons Attribution License (CC BY). The use, distribution or reproduction in other forums is permitted, provided the original author(s) and the copyright owner(s) are credited and that the original publication in this journal is cited, in accordance with accepted academic practice. No use, distribution or reproduction is permitted which does not comply with these terms. 